University of Wollongong

Research Online

Faculty of Engineering and Information

Faculty of Engineering and Information

Sciences - Papers: Part A

Sciences

$1-1-2012$

Impact of wind generator control strategies on flicker emission in distribution networks

Lasantha Meegahapola

University of Wollongong, lasantha.meegahapola@rmit.edu.au

Sarath Perera

University of Wollongong, sarath@uow.edu.au

Follow this and additional works at: https://ro.uow.edu.au/eispapers

Part of the Engineering Commons, and the Science and Technology Studies Commons

Research Online is the open access institutional repository for the University of Wollongong. For further information contact the UOW Library: research-pubs@uow.edu.au 


\title{
Impact of wind generator control strategies on flicker emission in distribution networks
}

\begin{abstract}
Renewable power generators are increasingly being integrated to electricity networks to achieve future renewable energy targets in power generation. In particular, wind power generation has already reported substantial penetration levels in electricity networks. Traditionally, flicker phenomenon is considered to be one of the power quality issues in power distribution networks due to fluctuating consumer loads connected to the network. Large-scale integration of wind power generators may create significant voltage fluctuations in distribution feeders due to stochastic and intermittent nature of the wind resources. This study aims to investigate and characterize the flicker emission under different control strategies for DFIG based wind generators. This study demonstrates a direct correlation between flicker emission and wind generator control strategies under different wind and network conditions. Therefore, additional control strategies should be implemented together with the main control strategy to reduce flicker emission during variable wind conditions.
\end{abstract}

\section{Keywords}

distribution, emission, flicker, networks, strategies, impact, control, generator, wind

Disciplines

Engineering | Science and Technology Studies

\section{Publication Details}

L. Meegahapola \& S. Perera, "Impact of wind generator control strategies on flicker emission in distribution networks," in IEEE ICHQP 2012, 2012, pp. 612-617. 


\title{
Impact of Wind Generator Control Strategies on Flicker Emission in Distribution Networks
}

\author{
Lasantha Meegahapola, Member, IEEE, and Sarath Perera, Member, IEEE
}

\begin{abstract}
Renewable power generators are increasingly being integrated to electricity networks to achieve future renewable energy targets in power generation. In particular, wind power generation has already reported substantial penetration levels in electricity networks. Traditionally, flicker phenomenon is considered to be one of the power quality issues in power distribution networks due to fluctuating consumer loads connected to the network. Large-scale integration of wind power generators may create significant voltage fluctuations in distribution feeders due to stochastic and intermittent nature of the wind resources. This study aims to investigate and characterize the flicker emission under different control strategies for DFIG based wind generators. This study demonstrates a direct correlation between flicker emission and wind generator control strategies under different wind and network conditions. Therefore, additional control strategies should be implemented together with the main control strategy to reduce flicker emission during variable wind conditions.
\end{abstract}

Index Terms-doubly-fed induction generator (DFIG), flicker emission, power factor control, reactive power control, voltage control.

\section{INTRODUCTION}

$\mathrm{P}$ OWER quality is of significant concern to distribution system operators (DSOs) to fulfill their customer satisfaction. Renewable power integration has introduced power quality issues in power distribution networks. Harmonics and flicker emission are identified as the major power quality issues associated with renewable power integration [1-2]. In particular, the variable nature of wind generation will result power fluctuations in remote distribution feeders hence result in flicker emission. Flicker effect conventionally occurs due to fluctuating consumer loads connected to distribution feeders [3]. Distributed renewable energy sources have introduced a paradigm shift in conventional passive power distribution networks while resulting bidirectional power flows in the networks. Consequently, flicker emission will result from fluctuating generating sources installed in distribution networks. A number of studies have been conducted during the past on flicker emission analysis [4-8], propagation [9] and mitigation techniques on wind generators [10-12].

The study conducted by Larson analyzed the effect of flicker emission for a fixed-speed wind generator [4]. Flicker study conducted by Moura etal. [5] advocated that flicker emission may limit the installable wind capacity to a radial distribution feeder. In [6] the authors have analyzed

This work has been financially support by Endeavour Energy, NSW, Australia.

Lasantha Meegahapola and Sarath Perera are with the Endeavour Energy Power Quality and Reliability Centre, University of Wollongong, Wollongong, 2500, Australia. (e-mail: lasantha@uow.edu.au, sarath@uow.edu.au). various factors affecting the flicker emission from wind farms, such as mean wind speed, turbulence intensity, shortcircuit ratio (SCR) and grid impedance angle (X/R ratio). A wind farm flicker emission study conducted in Turkey [7] has shown that wind farms at two locations have exceeded their emission limits stipulated by grid code standards. However, these studies are limited to a single operating strategy and effect of multiple renewable generators has not been investigated. This paper aims to characterize the flicker emission under different control strategies (e.g. power factor control, voltage control and fixed reactive power dispatch) implemented for a doubly-fed induction generator (DFIG) based wind farm. The DIgSILENT Power Factory was used as the main simulation tool for this study.

This paper is organized as follows: Wind generator control strategies and their impact on flicker emission are delineated in Section II. Section III exemplifies the test network model, DFIG model and its reactive power capability. Flicker emission analysis under different wind and network conditions are presented in Section IV. Finally, conclusions are presented in Section V.

\section{FLICKER EMISSION AND WIND GENERATOR CONTROL STRATEGIES}

Variable wind conditions cause power fluctuations in wind farms, causing voltage variations at the point of grid connection. This phenomenon can be understood by considering a generator feeding active and reactive power to an external grid via a distribution line as shown in Fig. 1.

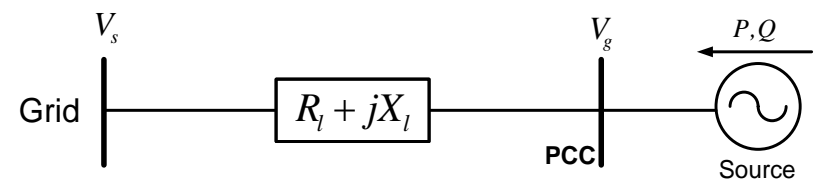

Fig 1. Single machine system.

$R_{l}, X_{l}, V_{s}, V_{g}, P$ and $Q$ denote distribution line resistance, distribution line reactance, grid voltage, generator voltage, active power and reactive power respectively. Voltage fluctuation $(\Delta V)$ due to variable active and reactive power output from a grid connected generator can be shown to take the form:

$$
\Delta V=\frac{R_{l}(\Delta P)+X_{l}(\Delta Q)}{V_{g}}
$$

The wind speed fluctuations will result fluctuations in active power output $(P)$, and hence will lead to voltage fluctuations $(\Delta V)$ at the generator terminal. Consequently, voltage fluctuation will lead to flicker emission in distribution feeders. However, the change in reactive power output $(\Delta Q)$ is mainly determined by the control strategy of the renewable generator, and hence according to (1) it will also influence flicker emission. Therefore, following 
reactive power $(Q)$ control strategies are evaluated during variable power generation.

- Power factor control strategy

- Voltage control strategy

- Fixed reactive power dispatch strategy

\section{A. Power factor control strategy}

Power factor control strategy is the most common control strategy implemented at wind farms. Many wind farms are operated either at unity power factor or at a leading power factor. A block diagram of the power factor control strategy is shown in Fig 2.

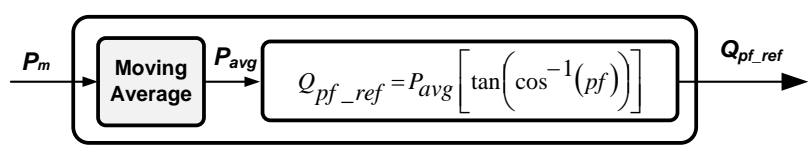

Fig 2. Power factor control scheme.

$P_{m}, P_{a v g}, Q_{p f \_r e f}$, and $p f$ denote the active power measurement, moving average of the active power output, the reactive power reference for power factor control, and the power factor reference respectively. Assuming unity power factor operation for the wind generator, (1) can be deduced to following:

$$
\Delta V=\frac{R_{l}(\Delta P)}{V_{g}} \Rightarrow \Delta V=\left(\frac{R_{l}}{V_{g}}\right) \Delta p
$$

According to (2) voltage fluctuations are directly governed by the active power fluctuations of the wind farm. However, when power factor control strategy is implemented (other than unity power factor) reactive power output is determined based on the average active power output of the wind generator and hence reactive power deviation can be denoted as follows:

$\Delta Q=K_{p f}(\Delta P)$

$K_{p f}$ is the multiplication constant for power factor correction, which is based on the operating power factor of the wind generator. By substituting (3) in (1):

$$
\Delta V=\frac{R_{l}(\Delta P)+X_{l}(\Delta P) K_{p f}}{V_{g}}
$$

$\Delta V=\left[\frac{R_{l}+X_{l} K_{p f}}{V_{g}^{2}}\right] V_{g} \Delta P \Rightarrow\left[\frac{\cos \left(\psi_{k}\right)+\sin \left(\psi_{k}\right) K_{p f}}{S_{k}}\right] V_{g} \Delta P$

$\psi_{k}$, and $S_{k}$ denote the grid impedance angle, and short-circuit apparent power respectively. For a given network condition $V_{g}, \psi_{k}$, and $S_{k}$ remain constant. Therefore, any variation in wind generator active power output $(\Delta P)$ leads to voltage fluctuations, and hence result flicker emission.

\section{B. Voltage control strategy}

Voltage control strategy is also employed in wind farms for voltage stability improvement and network voltage management. The block diagram of the voltage control scheme is shown in Fig 3.

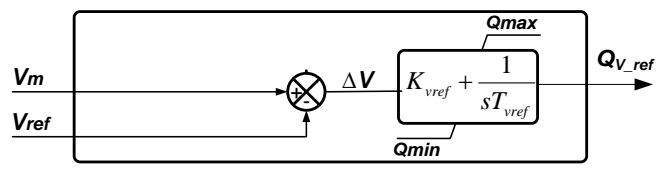

Fig. 3. Voltage control scheme.

$V_{m}, V_{\text {ref }}, K_{\text {vref }}$, and $T_{\text {vref }}$ denote voltage measurement at the wind farm, voltage reference, voltage control gain, voltage error integration time constant. The reactive power reference for the voltage control $\left(Q_{v_{-} \text {ref }}\right)$ scheme is updated every 100 ms. According to the voltage control strategy the reactive power change can be denoted as follows:

$\Delta Q=\left[K_{\text {vref }}(\Delta V)+\int_{0}^{t=T_{\text {vef }}} \Delta V d t\right]$

Substituting (2) in (5);

$\Delta Q=\left(\frac{R_{l}}{V_{g}}\right)\left[K_{\text {vef }}(\Delta P)+\int_{0}^{t=T_{\text {ref }}} \Delta P d t\right]$

Substituting (6) in (1);

$\Delta V=\frac{R_{l}(\Delta P)+X_{l}\left(\left(\frac{R_{l}}{V_{g}}\right)\left[K_{v r e f}(\Delta P)+\int_{0}^{t=T_{\text {vef }}} \Delta P d t\right]\right)}{V_{g}}$

A voltage deviation at the wind farm is governed by (7) and for ideal conditions $\Delta V$ must be maintained at zero. However, voltage controller is tuned considering moderate voltage variations at the wind generator terminal, and hence it is impotent to control voltage during large power fluctuations resulting from high wind turbulences. Therefore, voltage controller is incapable to maintain $\Delta V$ at zero during high wind turbulences and will result flicker emission.

\section{Reactive power dispatch strategy}

In recent years, power system researchers have examined the feasibility of using wind farm reactive power capability for system ancillary services [13]. The reactive power dispatch strategy generates constant reactive power output from a wind farm despite any active power fluctuations. Therefore, voltage fluctuations can be epitomized as given by (2), and hence flicker emission occurs due to fluctuations in active power output from the wind farm. However, this control strategy emulates behavior similar to a static synchronous compensator (STATCOM) and ultimately enforces a stiff voltage profile for weak networks.

\section{DFIG MODEL AND TEST NETWORK}

\section{A. The DFIG Model}

The total installed capacity of the wind farm considered in this study is $19.5 \mathrm{MW}(13 \times 1.5 \mathrm{MW})$ and consisted of GE $1.5 \mathrm{MW}$ wind turbine generators [14]. A schematic diagram of the DFIG simulation model is shown in Fig. 4.

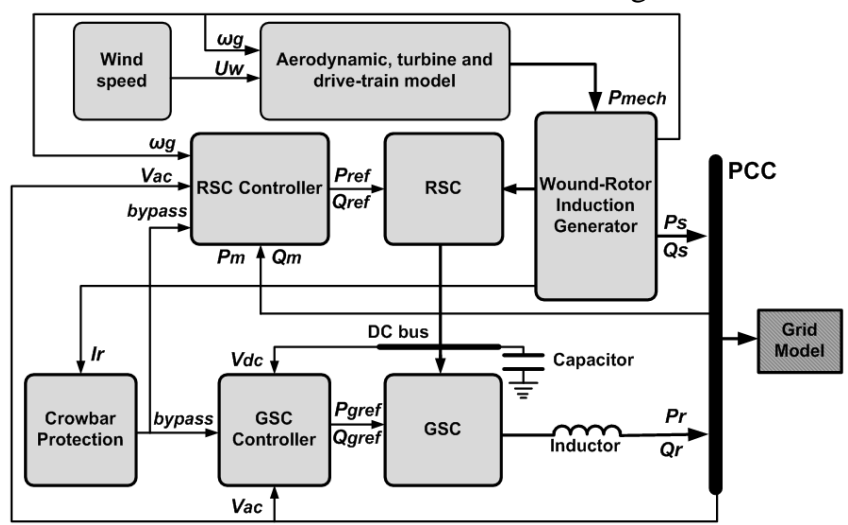

Fig. 4. DFIG simulation model.

$P_{\text {mech }}, P_{m}, P_{r e f}, P_{s}, P_{r}, P_{\text {gref }}, Q_{m}, Q_{r e f}, Q_{s}, Q_{r}, Q_{g r e f}, V_{d c}, V_{a c}, I_{r}$, $U_{W}, \omega_{g}$, denote the mechanical power input to the generator, 
active power measurement at PCC, RSC active power reference, active power output of the stator, grid-side converter (GSC) active power output, GSC active power reference, total reactive power measurement, rotor-side converter (RSC) reactive power reference, stator reactive power output, GSC reactive power output, GSC reactive power reference, DC link voltage, AC voltage at the PCC, rotor current, wind speed, and generator shaft speed. The steady-state performance of the DFIG simulation model was validated using measured data at an actual wind farm location [15].

\section{B. Reactive power capability of the DFIG}

The RSC reactive power capability is mainly constrained by the wound-rotor induction generator (WRIG) stator current, rotor current and rotor voltage limits [16-17]. These limiting factors further depend on the operating slip of the machine, and hence individual capability curves were produced for each slip value. The reactive power capability values for the intermediate slip values are calculated by a linear approximation function in DIgSILENT Power Factory. Fig. 5 illustrates the capability chart derived for the 1.5 MW DFIG-RSC using the generator parameters given in the Appendix.

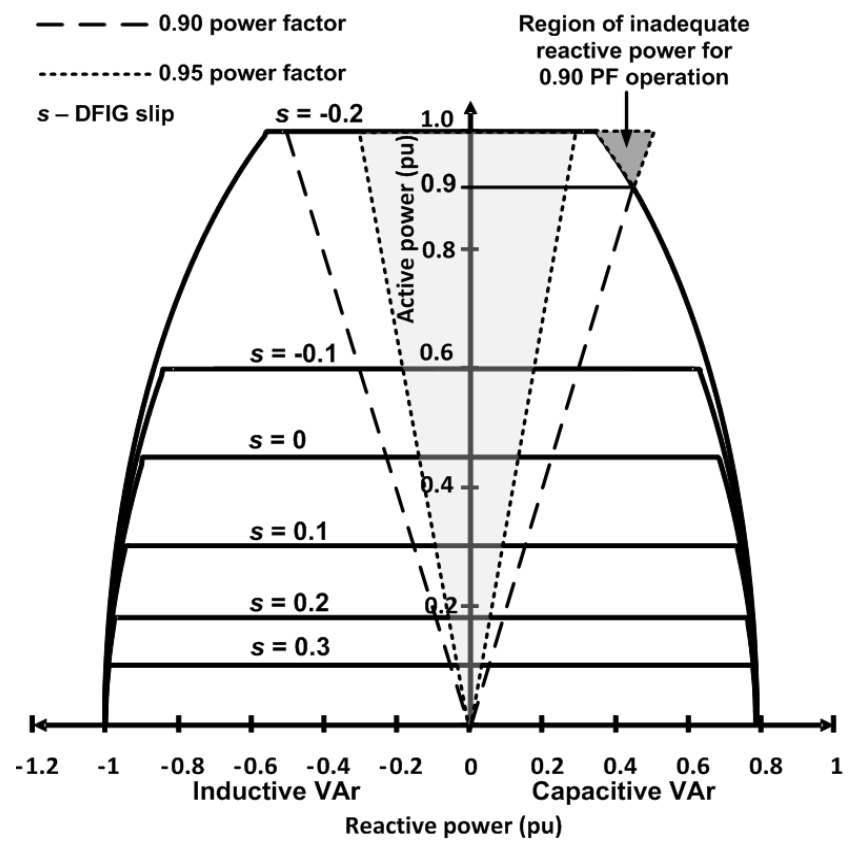

Fig. 5. DFIG-RSC reactive power capability chart.

The DFIG-RSC can operate between \pm 0.95 power factor across the operating range of the DFIG without additional reactive power support from the GSC. However, +0.90 power factor operation is limited to $0.90 \mathrm{pu}$ active power output and hence additional reactive power must be provided by the GSC during such conditions. In addition, the reactive power capability reduces with an increase in DFIG active power output.

\section{DFIG GSC reactive power capability}

Extended reactive power capability can be obtained by GSC of the DFIG and hence a separate reactive power capability chart was derived for the GSC of the DFIG. The GSC reactive power capability is mainly limited by the DC link and the back-to-back converter ratings. The GSC capability chart was also derived in order to dispatch reactive power independently while coordinating with the RSC. The GSC reactive power capability $\left(Q_{g c}\right)$ depends on the active power transfer through the GSC $\left(P_{g c}\right)$ and the operating slip of the machine [16]. The 1.5 MW DFIG GSC capability chart for the $30 \%$ and $50 \%$ converter rating is illustrated in Fig. 6.

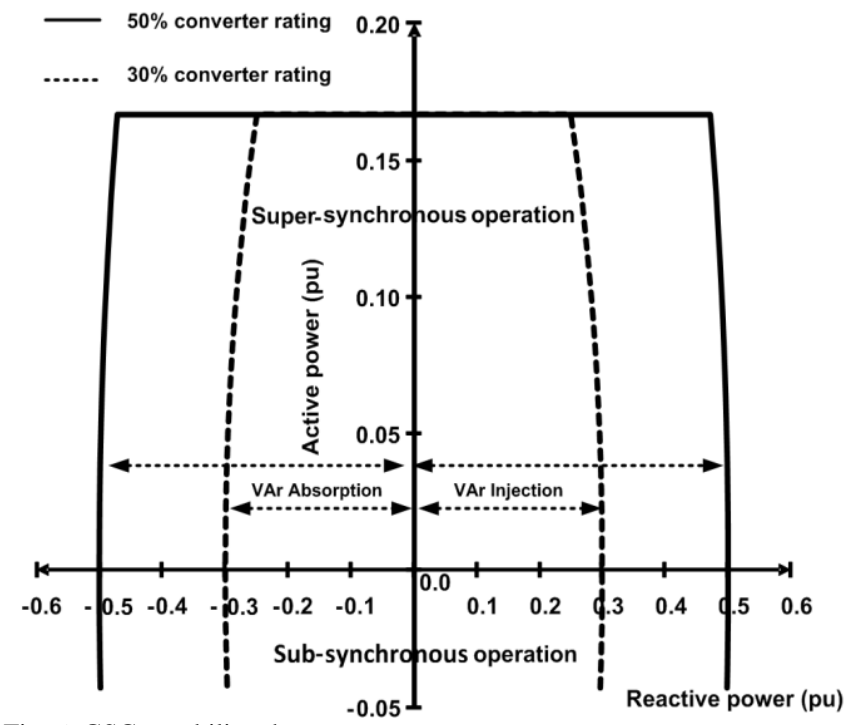

Fig. 6. GSC capability chart.

The vertical axis represents the active power while the horizontal axis represents the reactive power transfer through the GSC, they are normalized based on the rated active power output of the DFIG. The GSC capability chart indicates \pm 0.28 pu average reactive power capability for a $30 \%$ converter rating across its operating range while for a $50 \%$ converter rating the average reactive power capability increases to $\pm 0.48 \mathrm{pu}$. Therefore, a $50 \%$ converter rating indicates a combined reactive power capability of $1.28 \mathrm{pu}$ during zero active power production, while during full active power production this reduces to $0.83 \mathrm{pu}$. Consequently, the DFIG possesses significant reactive power capability to support network requirements.

\section{Test network}

A test system was developed (see Fig. 7) in DIgSILENT Power Factory considering an aggregated wind farm model which is connected to the transmission system by a $33 \mathrm{kV}$, $10 \mathrm{~km}$ long distribution feeder $(\mathrm{X} / \mathrm{R}=1)$.

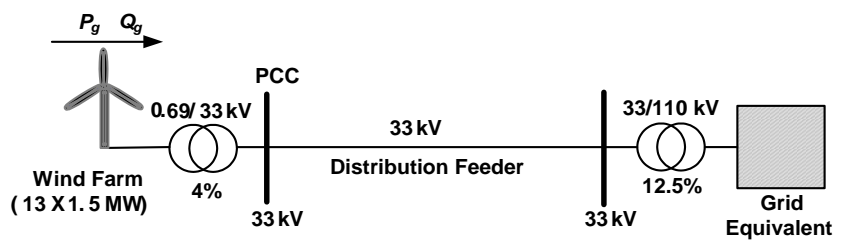

Fig. 7. Test network model for flicker emission analysis.

The short-circuit apparent power at the grid connection point is 2500 MVA which ultimately results in a shortcircuit ratio (defined as short-circuit apparent power divided by the wind farm MVA rating) of 115.4 at the point of grid connection. The DFIG wind farm assumed to have reactive power capability from both RSC and GSC. The RSC was operated as the main reactive power controller while GSC as the extended controller when reactive power requirement exceeds the limits of the RSC.

\section{FLICKER EMISSION ANALYSIS}

Flicker emission from the wind farm was analyzed considering different wind profiles and network conditions using the test network in Fig. 7. The short-term flicker severity $\left(\mathrm{P}_{\mathrm{st}}\right)$ was used as the main index to analyze the 
flicker emission under different control strategies for the wind farm. The short-term flicker severity was measured in accordance with IEC 61000-4-15 [18]. Three operating strategies were operated at their extreme conditions to analyze the impact of flicker emission on distribution networks. Therefore, power factor control strategy was applied at 0.9 leading power factor, the voltage control setting was $1.05 \mathrm{pu}$ and the system reactive dispatch target was set at $0.8 \mathrm{pu}$.

\section{A. Impact of wind profile characteristics}

Mean wind speed and turbulence intensity were used as the main parameters to characterize a wind profile. Previous studies have shown that these two parameters influence flicker emission from wind generators [6]. A sensitivity analysis has been carried-out assuming an X/R ratio of 1 for the transmission line and a SCR of 115.4 at the grid connection point. The different mean wind speed values used for dynamic simulations indicate various operating points (i.e. cut-in, linear and cut-off regions) of the maximum power tracking (MPT) curve of the DFIG [20].

\section{1) Impact of mean wind speed}

The short-term flicker severity and average reactive power for a range of mean wind speeds are shown in Fig. 8.
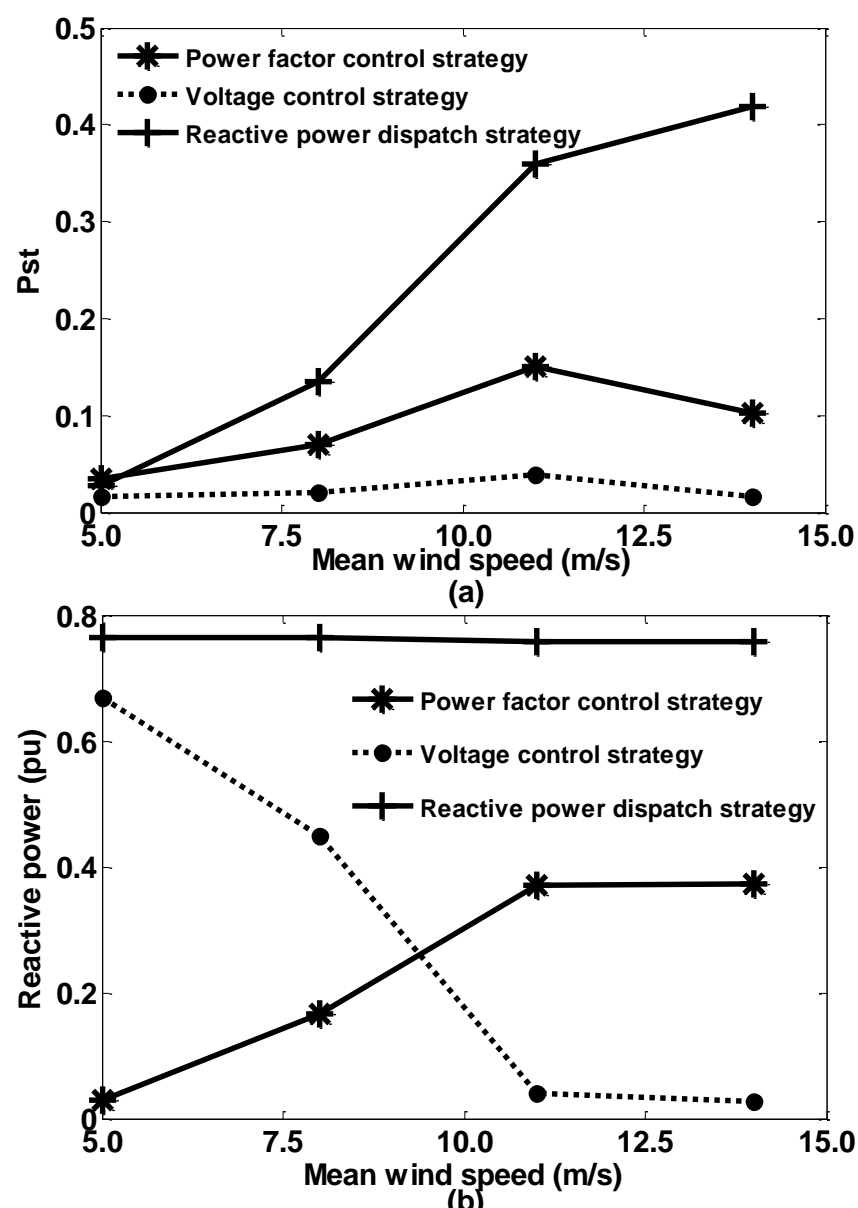

Fig. 8. Flicker emission comparison between wind generator control strategies for different mean wind speeds (a) Short-term flicker severity $\left(\mathrm{P}_{\mathrm{st}}\right)(\mathrm{b})$ Average reactive power dispatch.

Comparatively high $\mathrm{P}_{\mathrm{st}}$ values can be observed (see Fig. 8) when the wind speed varies between $7.5 \mathrm{~ms}^{-1}$ and $11.25 \mathrm{~ms}$ ${ }^{1}$, since during this wind speed range wind turbine control strategy changes between power optimization and limitation strategies [20], which leads to much greater active power fluctuations. However, short-term flicker severity for the reactive power dispatch strategy further increases when wind speed exceeds $11.25 \mathrm{~ms}^{-1}$, since such an operating condition leads to reduction in DFIG reactive power capability below the target dispatch value (i.e. $0.8 \mathrm{pu}$ ) while resulting significant change in reactive power dispatch. Therefore, according to (1), when reactive power output changes voltage fluctuations at the PCC will be exacerbated.

High short-term flicker severity can be seen for the reactive power dispatch strategy compared to the voltage and power factor control strategies. As an example, at a wind speed of $14 \mathrm{~ms}^{-1}$ the flicker severity $\left(\mathrm{P}_{\mathrm{st}}\right)$ is 0.45 for the reactive power dispatch strategy while for the voltage and power factor control strategy it is only 0.016 and 0.102 respectively. This is because for $14 \mathrm{~ms}^{-1}$ wind speed DFIG is operating at its rated speed $(1.2 \mathrm{pu})$ while generating rated active power output, and ultimately the DFIG reactive power capability is limited to $0.78 \mathrm{pu}$ (see Fig. 5). This leads to a 0.02 pu reactive power deficit and eventually leads to a significant change in reactive power dispatch while introducing $\Delta Q$ component in (2).

In addition, the reactive power requirement for the voltage control strategy has been progressively decreased (see Fig. 8-(b)), since higher wind speeds imply higher active power output, but the reactive power capability to maintain the voltage at a higher value (i.e. $1.05 \mathrm{pu}$ ) is decreased. Furthermore, reactive power for power factor control strategy increases with higher mean wind speeds due to increase in active power output of the wind generator.

\section{2) Impact of wind turbulence intensity}

The short-term flicker severity and the average reactive power for a range of turbulence intensities are illustrated in Fig. 9.

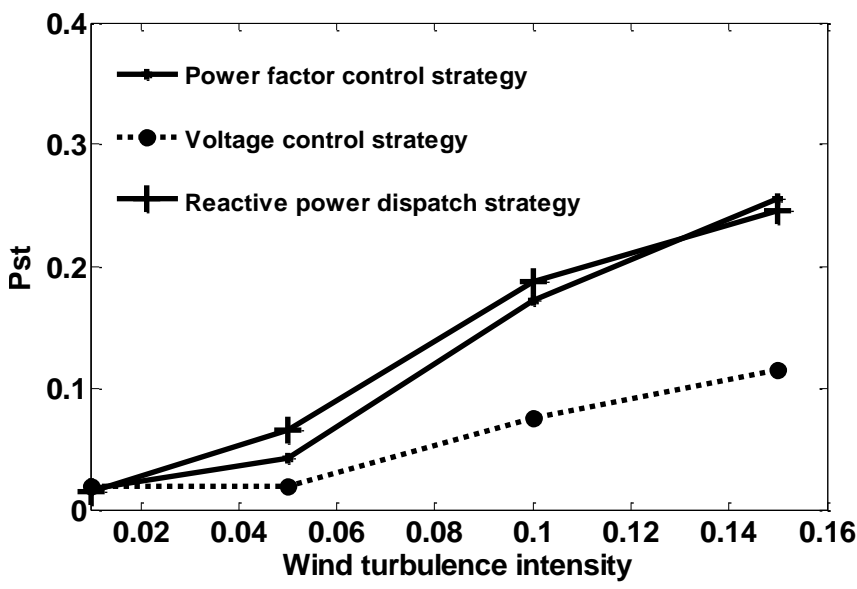

(a)

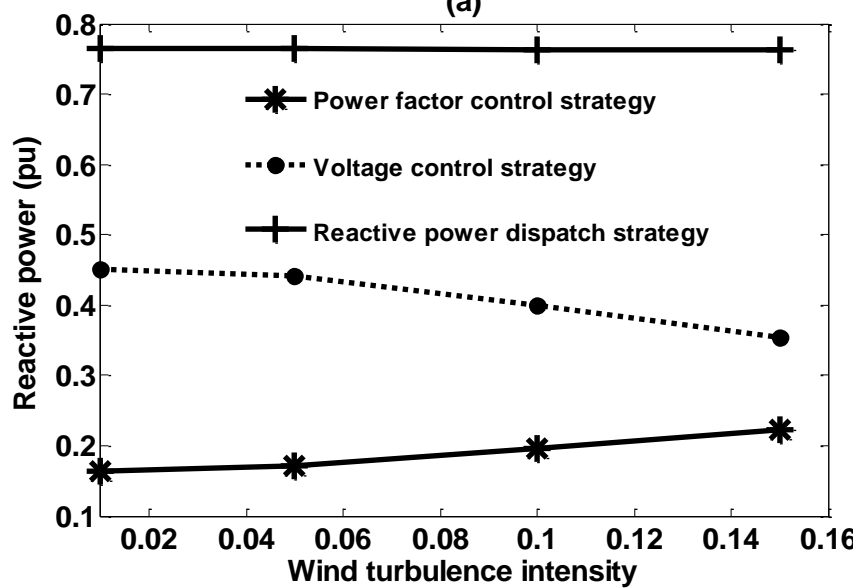

(b)

Fig. 9. Flicker emission comparison between wind generator contro strategies for different turbulance intensities (a) Short-term flicker severity $\left(\mathrm{P}_{\mathrm{st}}\right)$ (b) Average reactive power dispatch. 
High wind turbulence intensity has resulted in large $P_{s t}$ values due to the high active power fluctuations of the wind farm. This trend can be observed for all three wind generator control strategies. As an example, for the power factor control strategy there is a short-term flicker severity of 0.017 for 0.01 wind turbulence intensity which then increases to 0.26 at 0.15 wind turbulence intensity. Similar trend can be seen for both voltage and reactive power dispatch strategies when turbulence intensity increases. Average reactive power dispatch remains the same for reactive power dispatch strategy; however, it has been reduced for voltage control strategy due to an increase in mean wind speed as wind turbulence increase.

\section{B. Impact of network conditions}

The network conditions also affect the flicker emission, in particular the $\mathrm{X} / \mathrm{R}$ ratio (grid impedance angle $\left(\psi_{k}=\tan ^{-}\right.$ $\left.{ }^{1}(\mathrm{X} / \mathrm{R})\right)$ of the transmission line and the short-circuit ratio (SCR) of the grid connection point. A wind profile with mean wind speed of $6.6 \mathrm{~ms}^{-1}$ and turbulence intensity of 0.07 was used to perform the sensitivity analysis for network conditions. The $\mathrm{X} / \mathrm{R}$ ratio (grid impedance angle) was varied while maintaining the line impedance constant. $\mathrm{X} / \mathrm{R}$ ratios corresponding to grid impendence angles of $30^{\circ}$, $50^{\circ}, 70^{\circ}$, and $85^{\circ}$ were specifically chosen to comply with the flicker measurement standards [18-19].

\section{1) Impact of short-circuit ratio}

The short-term flicker severity and average reactive power for a range of SCRs are shown in Fig. 10.

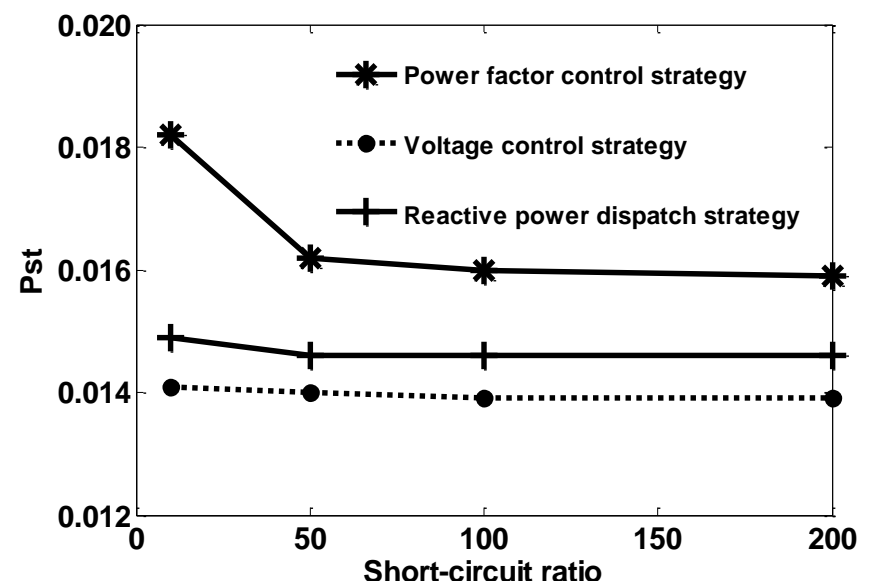

(a)

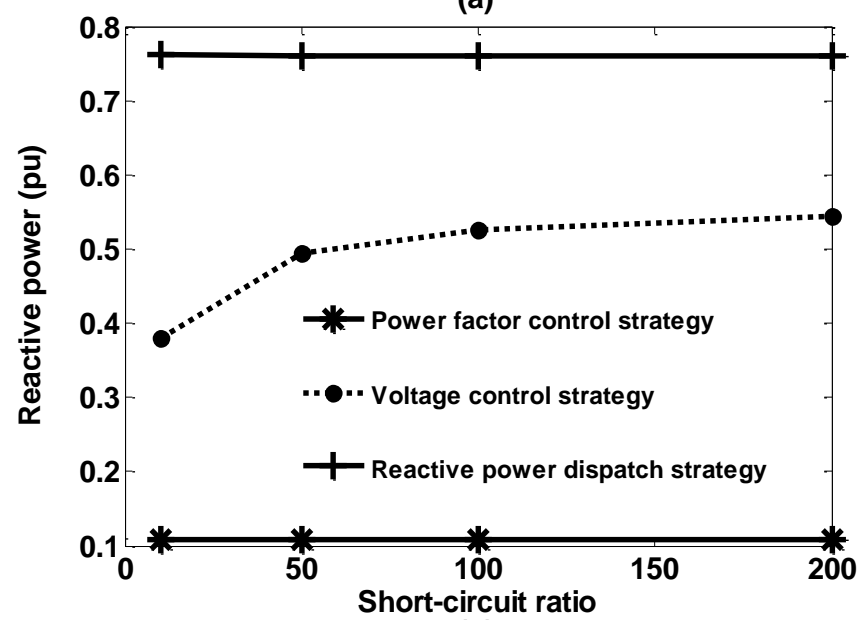

(b)

Fig. 10. Flicker emission comparison between wind generator control strategies for different short-circuit ratios (a) Short-term flicker severity $\left(\mathrm{P}_{\mathrm{st}}\right)(\mathrm{b})$ Average reactive power dispatch.
The short-term flicker severity has decreased with an increase in SCR (see Fig. 10-(a)) since the grid voltage becomes stiffer as SCR increases. As an example, for power factor control strategy it indicates $\mathrm{P}_{\mathrm{st}}$ of 0.018 at SCR 10 and that has reduced to 0.015 when SCR increases to 200 . The reactive power requirement for both the power factor control and reactive power dispatch strategies remains constant while that for the voltage control strategy indicates a steady increase with an increase in SCR. As an example, for a SCR of 10 the reactive power is $0.38 \mathrm{pu}$, but this increases to 0.54 pu when the SCR increases to 200. This is because when the $\mathrm{SCR}$ is increased the grid voltage exceeds beyond $1.05 \mathrm{pu}$, and hence reactive power must be absorbed to maintain the voltage at the stipulated value.

\section{2) Impact of $X / R$ ratio}

The short-term flicker severity and average reactive power for a range of $\mathrm{X} / \mathrm{R}$ ratios are shown in Fig. 11

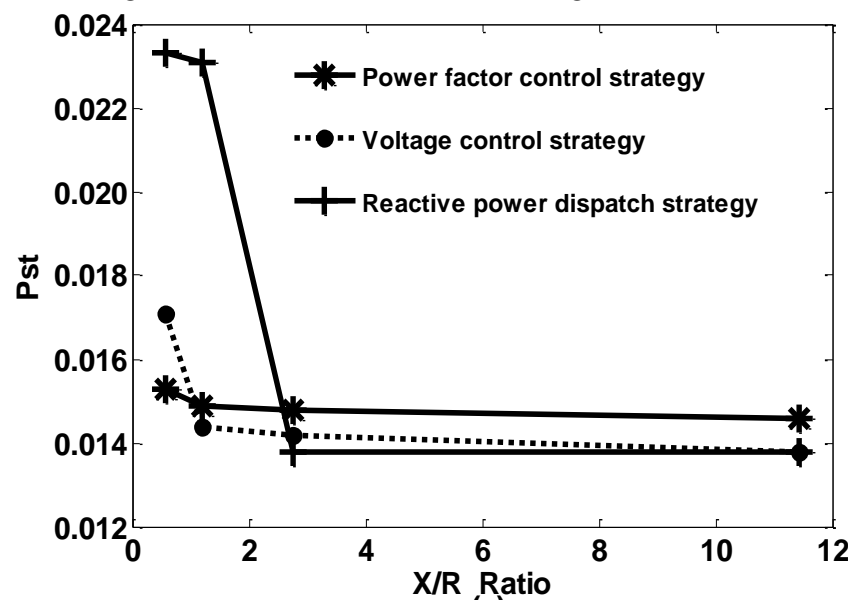

(a)

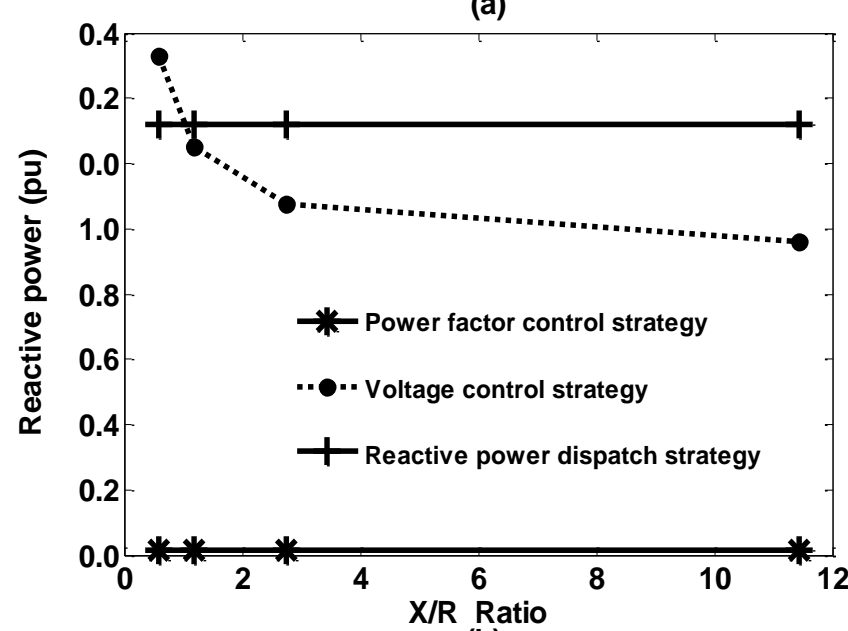

(b)

Fig. 11. Flicker emission comparison between wind generator control strategies for different $\mathrm{X} / \mathrm{R}$ ratio (a) Short-term flicker severity $\left(\mathrm{P}_{\mathrm{st}}\right)$ (b) Average reactive power dispatch.

The increase in $\mathrm{X} / \mathrm{R}$ ratio has significantly reduced the flicker emission for all three strategies as a consequence of the reduction in active power dependency of the voltage due to low line resistance. As an example, for the system reactive power dispatch strategy the short-term flicker severity is 0.0233 for an $\mathrm{X} / \mathrm{R}$ of 0.58 , which then reduces to 0.014 when the $\mathrm{X} / \mathrm{R}$ ratio increases to $11.4\left(85^{\circ}\right.$ grid impedance angle). In addition, the reactive power requirement has also been significantly reduced with an increase in the $X / R$ ratio, since the voltage fluctuations were reduced due to the weakened voltage dependency on active power. 


\section{CONCLUSIONS}

This study has investigated the impact of wind generator control strategies on flicker emission in distribution networks under different network and wind conditions. Study has shown that wind generator control strategy influences flicker emission under different wind and network conditions. Reactive power capability of the wind farm has also influenced on flicker emission, since during extreme wind turbulences it leads to large changes in reactive power due to limitations in generator reactive power capability, and consequently leads to large voltage fluctuations. If reactive power requirement remains within the DFIG reactive power capability it can stabilize the voltage fluctuations in a distribution feeder while acting as a STATCOM. Nevertheless, flicker emission may detrimentally increase if all worst conditions for both network and wind profile persist in a network.

Future studies will investigate the flicker mitigation scheme for the DFIG based wind generators operating under different control strategies. In addition, influence of the wind generator reactive power capability on flicker mitigation and impact on other fluctuating installations connected to distribution networks will also be investigated.

\section{APPENDIX}

1.5 MW DFIG parameters: rated stator voltage: $0.69 \mathrm{kV}$; rated rotor voltage: $1863 \mathrm{~V}$; rated apparent power: 1,667 $\mathrm{kW}$; rated speed: $1800 \mathrm{rpm}$; no. pole pairs: 2; stator resistance: $0.01 \mathrm{pu}$; stator reactance: $0.1 \mathrm{pu}$; rotor reactance: $0.1 \mathrm{pu}$; rotor resistance: $0.01 \mathrm{pu}$; magnetizing reactance: 3.5 pu; generator inertia: $75 \mathrm{kgm}^{2}$; turbine inertia: 4,052,442 $\mathrm{kgm}^{2}$; shaft stiffness: $83,000,000 \mathrm{Nm} / \mathrm{rad}$.

\begin{tabular}{c|c|c|c}
\multicolumn{4}{|c}{ TABLE III: CONTROL PARAMETERS } \\
\hline \hline Parameter & value & Parameter & value \\
\hline$K_{R X}$ & 0.98 & $K_{\text {vref }}$ & 1.06 \\
\hline$T_{a v}$ & 0.6 & $T_{\text {vref }}$ & 0.1 \\
\hline \hline
\end{tabular}

\section{REFERENCES}

[1] B. Fox, D. Flynn, L. Bryans, N. Jenkins, D. Milborrow, M. O Malley, and R. Watson, Wind Power Integration: Connection and System Operation Aspects. London, U.K.: IET, 2007.

[2] T.E. McDermott, "Distributed Wind Evaluation Methodology," $A W E A$ WindPower 2009.

[3] International Electrotechnical Commission (IEC), IEC/TR 61000-3-7: Electromagnetic Compatibility-Part 3-7: Limits-Assessment of Emission Limits for the Connection of Fluctuating Installations to MV, HV and EHV Power Systems, Ed. 2. 2008.

[4] A. Larsson, "Flicker emission of wind turbines during continuous operation," IEEE Trans. Energy Conv., vol. 17, no. 1, pp. 114-118, Mar. 2002.

[5] A.P. de Moura, A.A.F. de Moura, "Analysis of Injected Apparent Power and Flicker in a Distribution Network after Wind Power Plan Connection," IET Renewable Power Generation, vol. 2, no. 2, pp. 113-122, Jun. 2008.
[6] T. Sun, Z. Chen, F. Blaabjerg, "Flicker Study on Variable Speed Wind Turbines with Doubly-Fed Induction Generators," IEEE Trans. Energy Conv., vol. 20, no. 4, pp. 896- 905, Dec. 2005.

[7] C. Kocatepe, A. Inan, O. Arikan, R. Yumurtaci, B. Kekezoglu, M Baysal, A. Bozkurt, Y. Akkaya, "Power Quality Assessment of GridConnected Wind Farms Considering Regulations in Turkey," Renewable and Sustainable Energy Reviews, vol. 13, no. 9, pp. 2553 2561, Dec. 2009

[8] B. Barahona, P. Sørensen, L. Christensen, T. Sørensen, H.K. Nielsen, X.G. Larsén, "Validation of the Standard Method for Assessing Flicker from Wind Turbines," IEEE Trans. Energy Conv., vol. 26, no. 1, pp. 373-378, Mar. 2011

[9] C.V. Moreno, H.M. Duarte, J.U. Garcia, "Propagation of Flicker in Electric Power Networks due to Wind Energy Conversions Systems," IEEE Trans. Energy Conv., vol. 17, no. 2, pp. 267-272, Jun. 2002.

[10] W. Hu, Z. Chen, Y. Wang, Z. Wang, "Flicker Mitigation by Active Power Control of Variable-Speed Wind Turbines With Full-Scale Back-to-Back Power Converters," IEEE Trans. Energy Conv., vol. 24 no. 3, pp. 640-649, Sep. 2009.

[11] Y.S. Kim; D.J. Won, "Mitigation of the Flicker Level of a DFIG Using Power Factor Angle Control," IEEE Trans. Power Deliv., vol. 24, no. 4, pp. 2457-2458, Oct. 2009.

[12] L. Meegahapola, B. Fox, D. Flynn, "Flicker Mitigation Strategy for DFIGs during Variable Wind Conditions," IEEE Power and Energy Society General Meeting 2010, Minneapolis, USA, Jul. 2010.

[13] E. Martinez, F. Sanz, J. Blanco, F. Daroca, and E. Jimenez, "Economic analysis of reactive power compensation in a wind farm: influence of Spanish energy policy," Renewable Energy, vol. 33, no. 8, pp. 1880-1891, Jan 2008.

[14] N.W. Miller, W.W. Price, and J.J Sanches-Gasca, "Dynamic modeling of GE 1.5 and 3.6 wind turbine generators," ver. 3.0, GE, Dec. 2003.

[15] L. Meegahapola, B. Fox, D. Flynn, "Flicker Mitigation Strategy for DFIGs during Variable Wind Conditions," MEPS 2010, Minneapolis, USA, Jul. 2010.

[16] T. Lund, P. Sørensen, and J. Eek, "Reactive power capability of a wind turbine with doubly fed induction generator," Wind Energy, vol. 10, pp. 379-394. Apr. 2007.

[17] S. Engelhardt, I. Erlich, C. Feltes, J. Kretschmann, and F. Shewarega "Reactive power capability of wind turbines based on doubly fed induction generators," IEEE Trans. Energy Conv., vol. 26, no. 1, pp. 364-372, Mar. 2011

[18] IEC 61000-4-15: Testing and measurement techniques-FlickermeterFunctional and design specifications. Ed. 2, 2010.

[19] IEC 61000-3-7: Assessment of emission limits for the connection of fluctuating installations to MV, HV and EHV power systems, Ed. 2, 2008.

[20] A.D. Hansen, C. Jauch, P. Sørensen, F. Iov, and F. Blaabjerg, "Dynamic wind turbine model in power system simulation tool DIgSILENT," Riso Report-1400, Dec. 2003.

\section{BIOGRAPHIES}

Lasantha Meegahapola (S'06, GS'08, M'11) is a lecturer in power engineering at University of Wollongong, Australia. He received a BSc. Eng. degree (First Class) from the University of Moratuwa, Sri Lanka in 2006, and a PhD from The Queen's University of Belfast, UK in 2010. His research interests include renewable power generation, power system stability, and intelligent approaches in power systems

Sarath Perera (M'95) received the B.Eng. degree in electrical power engineering from the University of Moratuwa, Sri Lanka, the M.Eng. degree from the University of New South Wales, Sydney, Australia, and the $\mathrm{Ph} . \mathrm{D}$. degree from the University of Wollongong, Wollongong, Australia. $\mathrm{He}$ had been a lecturer at the University of Moratuwa. Currently he is an Associate Professor with the University of Wollongong, where he is also the Technical Director of the Integral Energy Power Quality and Reliability Centre. 